\title{
Variaciones sobre la literatura: la inscripción autobiográfica
}

\author{
Jorge Panesi • \\ Universidad de Buenos Aires
}

Sin dudas, una cierta fidelidad hay en Derrida por la literatura, lo que no significa que esta pasión, esta fe o convicción esté exenta de una distancia especulativa que busca explicarla, darle razones, reacomodarla según el derrotero del propio pensamiento, un pensamiento que se concibe como estrategias siempre variables sin destino prefijado, como un cálculo incesante ante lo incalculable, destino errático que llamó destinerrancia. En ese destino errático, la literatura no fue tanto una compañera privilegiada por su utilidad combativa que le habría aportado las armas deconstructoras necesarias para demoler el edificio metafísico (como han creído algunos críticos literarios demasiado ansiosos o ingenuos en su afán por abolir las fronteras entre literatura y filosofía), sino más bien una acompañante que, teniendo un destino no menos errático, hay que cuidar porque nos cuida desde una distancia de irregular proximidad. En primer lugar, porque como cualquier discurso, la literatura no está menos expuesta a la irradiación metafísica y ella misma es parte del edificio a deconstruir, y en segundo lugar, porque como irónicamente parece decir Derrida en "La ley del género", "no mezclará los géneros" ${ }^{1}$. No se mezclarán, quizá, porque el derrotero institucional es diferente, y porque sus adherencias con una lengua particular (algo que las hermana en sus consecuencias y en sus efectos) están por igual históricamente atadas, una a las instituciones filosóficas, y la otra a las literarias. No se mezclarán, pero no podrían dejar de mezclarse. No podrían dejar de acompañarse.

En esa historia de acompañamientos, Derrida reconoce un interés temprano por los diarios, autobiografías y confesiones en un contexto adolescente que lleva la impronta de Sartre (esto es, y en sus propias palabras, "un nuevo contacto entre la filosofía y la literatura" que Sartre permitió en el escenario de la posguerra francesa). Un interés que tardíamente -en 1992- se ha complicado, pero que persiste sin perder su carácter de enigma inicial:

- Jorge Panesi enseña "Teoría literaria y análisis crítico" en la carrera de Letras de la Universidad de Buenos Aires. Ha escrito, entre otros textos, Críticas, donde compila ensayos sobre Derrida, Borges, Perlongher, Kamenszain, Puig, Felisberto Hernández. 
Lo que me interesa aún hoy no puede llamarse estrictamente "literatura" o "filosofía” ¿̨cuál es su nombre? Autobiografía sea tal vez el nombre menos adecuado, porque me sigue pareciendo el más enigmático, el más abierto, incluso hoy. ${ }^{2}$

En la entrevista que dio a Derek Attridge y Geoffrey Bennington ese impulso adolescente por la autobiografía se describe como narcisista (y por lo tanto, paradójico, según la ley de lo "propio"): el deseo de autobiografía (de leerla, pero también de escribirla) es un "sello", un repliegue de autoafectación que, sin embargo, no posee unidad alguna, ni completo cierre sobre sí. El impulso o el deseo autobiográfico es un "polílogo interno", una conversación con muchas voces que en principio vocifera hacia un exterior más inmediato como rebeldía contra la odiada familia (significaba -dice Derrida- "familias, yo os odio"), pero que también se abre a una enciclopédica totalidad, porque es un élan de totalidad que se encuentra tanto en la filosofía como en la literatura. Élan o deseo de totalidad, que como la presencia o la voz -más allá de lo que una lectura superficial permitiría suponer-, juegan un papel motor en cuanto ha escrito, como por ejemplo, en "Envois", la correspondencia amorosa y autobiográfica de La carte postale, en la que el deseo imposible y reiterado de una presencia eternamente postergada -y hasta diseminada-atormenta la escritura. Si el acontecimiento es la venida del otro, esta venida no tiene un único trayecto, pues el otro/la otra amados son, a su vez, otro "polígono interno" que envía trayectorias siempre disímiles, siempre diseminadas y no coincidentes. La autobiografía es deseo de totalidad, tanto como de auto-totalización imposible: esta es la paradoja que Derrida muestra insistentemente en sus textos autobiográficos, incitados, empujados a deconstruir todas las implicaciones, todos los espejismos y las trampas del prefijo "auto". Lo que se cierra sobre sí, como una ilusión, se abre no a una totalidad, sino más bien a una miríada de trayectos y trayectorias, a una multiplicidad de envíos cuyo estado de perpetuo errar, puede, como en su lectura de La carta robada ${ }^{3}$, no llegar a destino.

Lo que Derrida retrospectivamente llama la "tentación enciclopédica" o la "avidez enciclopédica” de su adolescencia, es un rasgo que extiende tanto al género autobiográfico (las confesiones tienen el afán o la avidez de decirlo todo), como a la literatura o la filosofía:

...el discurso filosófico es con frecuencia nada más que una formalización económica de esta avidez ${ }^{4}$.

Insistentemente, "la inscripción autobiográfica" (como llamó al acontecimiento singular, a la firma singular que obra en el discurso literario y que es indisociable de su poder para formalizar cuestiones teóricas, históricas, lingüísticas y enciclopédicas ${ }^{5}$ ) termina por adherirse, por engramparse con pleno derecho teórico en muchas de las cuestiones, o en las mismas cuestiones filosóficas que Derrida ha abordado. Quizá sea El monolingüismo del otro, donde esa inscripción autobiográfica proyectada íntimamente sobre la candente cuestión (problema, desacuerdo incesante y cuestionamiento) de la lengua materna figure con mayor interpenetración, con mayor y pertinente resonancia mutua. La propiedad y la pertenencia respecto de una lengua que trazan la encrucijada de una paradoja ("no tengo más que una lengua y no es la mía") ${ }^{6}$, junto con el tema de lo propio expropiado que obra en la autobiografía, surgen indiscerniblemente del teatro colonial donde la herida de la exclusión lo ha marcado como si hubiese sido circuncidado por segunda o enésima vez, y también, y al mismo tiempo, de la especulación teórica que metafóricamente generaliza lo singularmente encarnado. 
En la historia de interdicción y de exclusión argelina (escolar, legal, nacional, lingüística) que Derrida ha contado varias veces con una insistencia que atañe a la dimensión histórica y política del acontecimiento, existe un núcleo institucional que se refiere a la escuela, a la escolaridad colonial y que quizá sea el comienzo de una sensación incómoda que ha experimentado frente a las instituciones filosóficas francesas, una posición central, sin duda, pero regateada, admitida, pero insidiosamente silenciada, murmurada. Esta interior excentricidad institucional (permítaseme el juego de palabras), en la nacionalidad, en la escolaridad, y finalmente en las instituciones filosóficas parece dictar el mandato teórico temprano de deconstruir, más allá del texto, el entramado institucional, y parece guiar también su acción fundadora respecto de esas mismas instituciones ${ }^{7}$.

El interés por la historia de las instituciones filosóficas en la que se juega una parte importante de la tarea deconstructiva tiene un interés paralelo: pensar la singularidad institucional de la literatura. Si el destiempo de su tesis doctoral le hace discriminar y excluir ante la ley académica las obras más "literarias" que presenta ante el tribunal (entre ellas Glas $^{8}$ ), el recuento de su historia académica frente al tribunal hace reaparecer el fantasma de una primera tesis nunca concluida, "La idealidad del objeto literario". La omisión de los textos más literarios o transgresores se compensa con la confesión pública, con la inscripción autobiográfica de un interés por la literatura:

Mi interés más constante, diría que anterior incluso al interés filosófico, si es posible, iba hacia la literatura, hacia la escritura llamada literatura? .

La matriz de la tesis inconclusa está en sus trabajos sobre la fenomenología ( $E l$ origen de la geometría) que -dice Derrida- "no han dejado de organizar las investigaciones que emprendí más adelante en torno a corpora filosóficos, literarios, incluso no-discursivos..." ${ }^{\prime 10}$. En efecto: el rigor de sus lecturas y el rigor en general al que suele aludir cuando se refiere a los protocolos necesarios para tratar con textos y contextos tiene como modelo a Husserl, por lo tanto, no nos debe extrañar que reivindique un vocabulario fenomenológico para una lectura deconstructiva de la literatura, en particular el concepto de "objeto intencional", pero haciendo depender la intencionalidad de la convención y la institucionalidad:

Esto no quiere decir que sea meramente proyectivo o subjetivo, el capricho de un lector. El carácter literario de un texto está inscripto en el aspecto de objeto intencional, en su estructura noemática, y no solamente en el aspecto subjetivo del acto noético. Existen "en" el texto elementos que reclaman una lectura literaria y recuerdan la convención, la institución o la historia de la literatura. Esta estructura noemática está incluida (como "no real" en los términos de Husserl) en la subjetividad, pero una subjetividad que no es empírica y que está ligada con una comunidad intersubjetiva y trascendental. Creo que este tipo de lenguaje fenomenológico es necesario, incluso si la literatura pone en crisis hasta cierto punto a la fenomenología, y hasta el mismo concepto de institución o de convención, social en todo caso. ${ }^{11}$

¿En qué consiste la dimensión institucional de la literatura? En Pasiones, Derrida ata su poder singular, único, de "decirlo todo" (en esto es fiel a sus primeras intuiciones adolescentes ${ }^{12}$ ) a la democracia ("no hay literatura sin democracia, ni democracia sin literatura"). Lo que equivale a decir que es una institución nueva de Occidente, una institución europea, cuya compleja y particular historia no es exportable hacia los textos de la antigüedad, ni tampoco a una ubicua universalidad. El "decirlo todo" de su free speech democrático tiene un precio: la irreductible ficcionalidad de esta institución sui generis, por la cual todo lo que dice es, como 
un resto, literatura. Pero la historia que la ata a la democracia (recordemos que la democracia, para Derrida, está por venir) le otorga la posibilidad (la literatura es nada más que posibilidad) de decir no sólo más allá de la pena, la censura o el castigo, sino de decir lo que todavía no tiene porvenir, lo inauditamente nuevo, lo radicalmente otro, lo que carece de palabra y de lenguaje. Por eso Derrida une la literatura con el secreto y con la responsabilidad sin límites, sin ataduras ni fronteras. Es la irrestricta o hiperbólica responsabilidad de la literatura que nace, paradójicamente, de su irresponsabilidad, de su posible no responder, no sólo ante los poderes que le exigen la responsable respuesta (y este es uno de los rasgos políticos más deseables de su relación con la democracia), sino también ante el secreto (que no es el misticismo de lo escondido, lo sustraído, lo desviado, lo no develado). Se trata, según Derrida, "del secreto ejemplar de la literatura": "una posibilidad de decirlo todo sin tocar el secreto", de dejarlo tal cual, es decir, como lo siempre radicalmente otro, lo que siempre está en la inminencia de un por venir ${ }^{13}$.

La apertura combinatoria que Derrida le imprime al género "autobiografía" le permite, reinventándolo, suspender las certezas ingenuas de quien lee (en Circonfessions las demostraciones "teológicas" o teóricas de Bennington, el otro que predica y solidifica desde arriba de la página). Sorprenderlo, desbaratarlo, pero -como en la literatura- sin tocar el secreto, porque el yo de la autobiografía nunca será la certeza de una identidad o la continuidad fantasmática que se reconoce en la filiación o en la sangre, sino el núcleo móvil de una ceguera constitutiva que se traslada al ritmo de cuanto se escribe. Tal vez, en el mismo movimiento de autoafectación que quiere dar cuenta de lo propio, se cuela lo otro, el otro, a quien verdaderamente la autobiografía llama, incita, solicita. En la autobiografía lo otro actúa ineluctable, certero y eficaz, pero sin nombre, no tiene nombre, aunque podría llamársele, invocársele con el nombre de muerte. La teoría derridiana de la escritura la nombra "tanatografía", y con un giro de complicación, auto-heterotanato-grafía. Nomenclatura que no se confunde jamás con eso mismo que roe por dentro la autobiografía.

En este sentido, decir que Jacques Derrida, como ningún otro, ha sido un filósofo mortuorio, es quizá demasiado brutal, y quizá también, inexacto. Es el filósofo de nuestra época que mejor ha sabido tejer con ese hilo de luto un entramado entre la vida y entre la muerte, la muerte propia y la de los otros. Es el filósofo del duelo -y esto es más exacto-: en el duelo se canta (no hay otra palabra y es la que él usa) desde la vida, por la vida y más allá de ella, por el porvenir. En Feu la cendre cita en español la ceniza de un verso de Quevedo ("polvo serán, mas polvo enamorado...") ${ }^{14}$ : ese es el tono -me parece- de cuanto ha escrito de autobiográfico (y no ha sido poco), un tono de canto ${ }^{15}$, es decir, de cercanía con las plegarias (con las plegarias y las lágrimas de Circonfessions), que siempre son una incitación a que algo advenga, el indicio incierto, no sabido, de un acontecimiento.

A ese no saber y a lo imprevisible (tópicos que la filosofía sólo acepta con desconcierto), Derrida los acechó desde múltiples ángulos, uno de los cuales ha sido el de la risa: "Me divierto mucho, me habré divertido mucho" -dice en Circonfessions $^{16}$, revelando un placer sin el cual el trabajo de la deconstrucción sería solamente penoso. Pero el trabajo, todo trabajo, según leemos en "Envíos"17 es un trabajo de duelo, con lo que, sin contradicción, Derrida puede también figurarse irónicamente a sí mismo como escatológico: "Siempre he sido escatológico [...] hasta el extremo, soy el último de los escatologistas ${ }^{18 "}$. 
En Parages (el libro dedicado a los textos de Blanchot) leemos que la literatura es ejemplar en su relación con lo inaccesible, otro nombre para el secreto innominado. Pero, de igual modo y en el mismo plano, la literatura se liga, como todo trabajo de escritura o de inscripción, con la muerte.

Lo inaccesible, lo imposible incita como un texto cifrado, y si la autobiografía experimenta con todas las formas escriturarias en una especie de apertura casi sin bordes y sin dejar de acariciar la muerte ("Tengo ganas de matarme" -dice en Circunfessions-); paralelamente Derrida, y tal vez sin proponérselo, ha despertado un género cuyas leyes retóricas no viola en lo más mínimo, el discurso fúnebre. Por eso aceptó la propuesta de publicar en inglés y francés una recopilación de estos discursos suyos que, sin renunciar a la grave ceremonia ni a su ancestral retórica, los convierte en lo más íntimo de lo íntimo, yuxtapuesto a la ceremonia más pública, la más expuesta. Pensamiento al borde de la muerte, compendio de cuanto ha pensado y renovado ante cada particular adiós, el discurso fúnebre, del cual es el último y anacrónico de los cultores, debe ser leído como otra forma de la inscripción autobiográfica, como otro trazo de un autorretrato cuyo secreto proviene de la muerte del otro: "La muerte proclama cada vez -escribe en el prólogo- el final del mundo en su totalidad, el final de todo mundo posible, y cada vez el final del mundo como totalidad única, por lo tanto irremplazable y por lo tanto infinita" 19 .

Escatológico, sí, el pensamiento de Derrida es el pensamiento de lo último, tanto, y por eso mismo, como lo es de aquello innominado que vendrá después de cada último. Es lo que le permite, con mayor derecho, ser un pensador afirmativo, el pensador del sí, y leer La folie du jour de Blanchot, y a Blanchot mismo, como un exaltador de la vida ${ }^{20}$.

Así como la autobiografía traza siempre la relación con la propia muerte, la literatura en su nacimiento institucional moderno, tal como lo describe Derrida, cuenta la muerte de la literatura misma ${ }^{21}$. En "Envíos" es donde Derrida le gusta pintarse como el último filósofo que ha mantenido una correspondencia en el sentido tradicional y convencional con el que lo entendemos (ligada al papel y al correo), también constata el término de una época en la que primaron cierto tipo de envios, el fin de toda una época postal que va desde Platón-Sócrates hasta Heidegger y Freud. En esta otra época, en cuyo pórtico estamos, la llamada "muerte de la literatura" (en rigor una posibilidad inscripta y acariciada ab initio en su propio discurso) parece destinada a una transformación que, al menos, hará morir nuestra concepción institucional de lo que llamamos literatura:

El fin de una época postal es sin duda también el fin de la literatura ${ }^{22}$.

La muerte o la transformación radical de la literatura bajo otra etapa de la telecomunicación, hay que recordarlo, es un avatar más, aunque decisivo, de la comunicación, pues en la teoría de Derrida toda comunicación es ya una tele-comunicación. En este sentido, no hay pesimismo alguno en su obra, porque en las estrategias de pensamiento que utilizó hay dos que permiten considerar de otro modo absolutamente distinto lo que apenas se deja ver como el futuro: la consideración del animal o lo animal, y el pensamiento de la máquina, lo maquínico, en obra más allá de la máquina misma, como por ejemplo, en el texto y en la autodeconstrucción del texto, pero también más allá de él ("máquinas hay en todas partes, y sobre todo en el lenguaje"23 -le responde a Élisabeth Roudinesco).

En Papier machine ${ }^{24}$, donde emprende una relectura de Rousseau junto a una 
relectura de Paul de Man (otra vez las Confesiones, otra vez la autobiografía), atisba lo inaudito de unir el acontecimiento, el pensar del acontecimiento, con un pensar la máquina: "Yo definiría la máquina como un dispositivo de cálculo y de repetición” ${ }^{25}$. Pensar la máquina donde no pensamos que esté, nos permitiría como a él, concebir la historia de la literatura también como compuesta, en parte, por automatismos y repeticiones ${ }^{26}$.

Si el texto es, como afirmó reiteradamente, "una máquina lectora" ${ }^{27}$, cabría preguntar qué tipo de lector espera quien inscribe su autobiografía, quien ha ensayado y desbaratado el género autobiográfico. Ni más ni menos que una especie de "lector total". En todo caso, el lector que se desprecia o la lectura que se desprecia es la del lector impaciente, el que resume para establecer las "posiciones" manifiestas de su autor, el que lee desde algún marco que no se revisa a sí mismo en la lectura, el que lee desde afuera siguiendo un patrón prefijado sin internarse en las laberínticas tramas del texto, el que busca la identidad a todo precio, la homogeneidad y la hegemonía. Para el caso del lector de autobiografías, es el que crédulamente espera leer el relato de una vida o saber la verdad de una vida, conocer su secreto. Lo que apaciguaría a tal lector de confesiones o autobiografías es "una divulgación decidible, porque los simulacros los vuelven locos ${ }^{28}$ ". Se trata en "Envíos" de no escamotearle al lector la experiencia de enloquecimiento que supone esta categoría de "indecidible" que vacila entre la experiencia, la realidad, la verdad, la retórica, la literatura (la buena y la mala), el disimulo y la ficción. Que en rigor actúan en cualquier autobiografía, pero que en Derrida se ponen en abismo hasta la exasperación.

En Circonfessions se imagina un lector total con la forma de una mirada telescópica, una especie de mirada de Dios, una mirada lectora que también produce miedo. Como la tarea lectora de la deconstrucción es infinita, semejante mirada es también un postulado necesario. Ese deseo de lectura total insiste: son los "si tuviera tiempo", los "esto exigiría un desarrollo más extenso", esparcidos por casi todos sus textos, que abren y abandonan a la vez el hilo de una lectura posible, y que muestran la tendencia y la posibilidad de leerlo todo como una red virtual de correspondencias cuya actualización es, por definición -y como diría él- posibleimposible. Pero si esa divina mirada total existiese, sería capaz de leer lo más secreto de lo secreto, volvería absolutamente público lo que constituye el corazón de la literatura, y la anularía como tal, le quitaría su relación con el secreto. Retrospectivamente, sin embargo, Joyce se le aparece como ese lector total que previó desde una babel de lenguas y traducciones los trayectos de la escritura moderna: "Joyce, ese que nos leyó y el que nos pilló a todos".

El lector deseado por Derrida lee la filigrana del texto, la tela virtual e histórica que forma la lettre, teje una red que no sólo es de sentido, sino de resonancias. El lector total de Derrida lee con el cuerpo, con unas ansias desmesuradas, con una avidez de apropiación caníbal: "el texto leído no basta, hay que comerlo, chuparlo ${ }^{29}$ ", y también lee como el adolescente argelino, desde un incierto saber, el de las lágrimas.

En las antípodas de ese lector, está el mal lector, el apresurado, el que jamás en su precipitación vuelve atrás, el que no relee. "Citar no es leer", dice Derrida en Un vers à soie. La lectura paciente, rigurosa, con todo el rigor y el deber micrológico debe respetar el cuerpo de lo que lee, no debe amputarlo, herirlo o desgarrarlo; a ese cuerpo se le debe respeto, hay que desatarlo, como si tuviera hilos de retención 
que lo anudaran; Derrida recuerda en "Envíos" el epistolen luein ${ }^{30}$ : desligar los cordones que pliegan una carta, seguirlos en el movimiento mismo que lo desata sin rasgar, sin herir, sin anular ni nulificar su cuerpo, y menos aún analizarlo. La lectura que Derrida reclama no es una lectura impiadosa.

Esta exigencia de lectura, esta solicitación de una labor extenuante, sin resquicios, desgrana en sus textos una serie de protestas y de quejas hacia los doctos lectores que no lo han leído, que no han emprendido el trabajo de leerlo. Son muchos, pero bastaría citar a Habermas o a Searle.

Se trate de autobiografías, literatura o filosofía, quien escribe testimonia en lo que lee y escribe una relación intransferible con la lengua. Que en el caso de Derrida no es la apacible morada heideggeriana, sino un hábitat atravesado por la intemperie y asentado en el abismo. El mal lector parece tener una relación cómoda con la lengua, cree poder cuantificarla u objetivarla, lee desde esta sensata convicción. A Derrida, en cambio, la lengua le provoca toda clase de insensateces, encrucijadas imaginarias, protestas, celos y amores. Con la lengua se mantiene una especie de teatro insensato, sin lógica, disparatado, sustraído a todo cálculo: no se cuantifica ni se objetiva, no se fabrica con ella ningún metalenguaje. En ese teatro ilusorio del escriba y su lengua, se imaginan relaciones de propiedad y apropiación imposibles. Hay una sola, y hay que hacerla cantar, como si fuera una puta (la puta es de todos, pero el canto que profiera será la obra de uno solo): "la puta que hay que hacer cantar", exclama en "Envíos".

El propietario desposeído por aquella que ama ("la lengua nos envenena el más secreto de nuestros secretos" ${ }^{\text {"11 }}$ ) sueña con inventar una lengua nueva, una nueva sintaxis, para no deberle nada a la "bienamada", pero la deuda es imborrable tanto como desatinada:

ella nos debe todo, la lengua francesa, ella a quien nosotros debemos aún más... ${ }^{32}$

La relación con la lengua forma una lógica absurda. El que lee o el que escribe siente que se ha vuelto loca: "Siempre sospeché - dice en El monolingüismo del otro- que la ley, como la lengua, estaba loca, o en todo caso, que era el único lugar y la primera condición de la locura" ${ }^{33}$. La lengua se ha vuelto loca porque se sustrae a toda lógica. La principal locura consistiría entonces en la segregación de una lengua totalmente nueva, una lengua del sí mismo como insensato secreto absoluto. Pero la imaginación de una lengua propia no deja de acechar, aun si el intento es desmesurado. Algo que Derrida atisba en los otros escritores: firmar la lengua en su totalidad con la marca de quien escribe, tal como lee en la poesía de Francis Ponge ${ }^{34}$, o la construcción de una babel translingüística, como en Joyce, o la contrafirma de toda la lengua alemana que descubre en Paul Celan ${ }^{35}$, quien a modo de una circuncisión le deja una cicatriz, una marca, una herida, y permite con ello que algo totalmente nuevo le advenga al alemán, como si tradujese al alemán dentro del alemán. La contrafirma sería una forma ejemplar de lectura, porque respeta el cuerpo de la lengua, el cuerpo del texto, haciéndole llegar, al mismo tiempo, algo totalmente otro, que apacigua también la desmesura de quien marca así el texto o la lengua sin ningún tipo de apropiación.

La relación con la lengua, la soledad de quien lee o escribe frente a esa lengua, traza un modo inusitado de responsabilidad que la literatura complejiza y amplifica. Es, como muestra Derrida en Donner la mort ${ }^{36}$, la lengua ajena e inhumana que habla Abraham a solas y en secreto con su Dios, pero es la lengua de Bartleby, que también habla en una lengua extraña, inhumana, la lengua de su propio sacrificio. 
¿Y que hay de la autobiografía en todo este teatro fantasmagórico, en todos esos velos? Se me ocurre que Derrida ha respondido a la pregunta cuando lee y responde a Voiles, el texto de Hélène Cixous. Su texto se llama Un ver à soie ${ }^{37}$. Esto es: "un gusano de seda", pero también "hacia sî", "hacia sí mismo", y "verso de seda". De esta respuesta me interesa el final, la inscripción autobiográfica, que es extrañamente para alguien que ha declarado su imposibilidad de narrar, una narración. Jacques, el niño argelino, ha cultivado gusanos de seda en una caja de zapatos. El gusano que fascina al niño teje con su cuerpo, segrega con su cuerpo la substancia textil que lo hará ir hacia sí, encerrarse en ese tejido blanco y esconderse de sí mismo. Segrega a partir de sí, hacia el afuera, lo que habrá de encerrarlo. Encierro temporario, secreto hasta la reconversión de sí, hasta el renacimiento que es la muerte de sí y la transformación en un afuera. Derrida no nos dice mucho sobre ese tejido caído, sobre ese incesante, laborioso capullo que cae. Más allá del secreto, lo que nos interesa es esa substancia textil, ese texto convertido en imposible propiedad de los otros, porque es un velo, y porque nada habría más allá de ese velo que todo lo hace posible.

\section{Notas}

${ }^{1}$ Jacques Derrida, "La loi du genre" en Glyph 7, 1980, pp. 177-210:

«Ne pas mêler les genres. Je ne mêlerai pas les genres. Je répète: ne pas mêler les genres. Je ne le ferai pas».

2 "Esa extraña institución llamada literatura" (entrevista con Derek Attridge y Geoffrey Bennington), en Derek Attridge (comp.), Acts of Literature. Jacques Derrida, New York y Londres, Routledge, 1992. Mi traducción.

3 "Le facteur de la vérité", en La carte postale de Socrate à Freud et audelà, París, Flammarion, 1980. Apareció por primera vez en Poétique 21, 1975.

${ }^{4}$ En Derek Attridge, op. cit.

${ }^{5}$ En Derek Attridge, op. cit.

${ }^{6}$ Le monolinguisme de l'autre ou la prothèse d'origine, París, Éditions Galilée, 1996. Cito por la traducción castellana, El monolingüismo del otro, Buenos Aires, Manantial, 1997, p. 14.

${ }^{7}$ La creación junto con otros filósofos del Groupe de Recherches sur L'Enseignement Philosophique (GREPH). A esta actividad "combativa" se refiere en la defensa de tesis. Cfr "El tiempo de una tesis: puntuaciones", Anthropos 93, 1989, p. 25 (traducción de Patricio Peñalver).

8 “... tras las tres obras publicadas en 1972 he seguido practicando la misma problemática, la misma matriz abierta [...] en dirección a configuraciones textuales cada vez menos lineares, a formas lógicas y tópicas, incluso tipográficas más arriesgadas, cruce de corpora, mezcla de géneros o modos, Wechsel der Töne, sátira, tergiversación, injerto, hasta el punto de que todavía hoy, aun cuando están publicados desde hace años, no he osado, no he considerado oportuno inscribirlos aquí entre los trabajos a defender como doctorado. Esto afecta también a Glas...”. En “El tiempo 
de una tesis: puntuaciones", cit, p. 24.

9 "El tiempo de una tesis: puntuaciones", cit, p. 21.

10 "El tiempo de una tesis: puntuaciones", cit, p. 22.

${ }^{11}$ Derek Attridge, Acts of Literature, op. cit., p. 44. Mi traducción.

12 "La literatura me parecía (en la adolescencia), de una manera confusa, la institución que nos permite decirlo todo (tout dire) de cualquier modo", en Derek Attridge, Acts of Literature, op. cit.

13 "Hay en la literatura, en el secreto ejemplar de la literatura, una posibilidad de decirlo todo sin tocar el secreto. Cuando todas las hipótesis están permitidas, sin fondo e infinitamente, acerca del sentido de un texto, o acerca de las intenciones finales de un autor cuya persona no está ni más ni menos representada que no representada por un personaje o por un narrador, por una frase poética o ficcional que se desgaja de su fuente presunta y permanece así en secreto; cuando ya no hay siquiera un sentido a decidir sobre un secreto cubierto tras la superficie de una manifestación textual (y es esta la situación que yo llamo texto o huella); cuando se trata del llamado de ese secreto que, sin embargo, remite al otro o a otra cosa; cuando es eso mismo lo que mantiene nuestra pasión en suspenso y nos retiene en el otro, entonces el secreto nos apasiona. Inclusive si el secreto no es secreto, incluso si nunca hubo un secreto, un solo secreto. Ni uno". En Passions, París, Galilée, 1993, [mi traducción].

${ }^{14}$ JacQues DerRIDA, Feu la cendre, París, Editions des femmes, 1987, p. 59. ${ }^{15}$ "Je crois vraiment que je chante quelqu'un qui est mort et que je n'ai pas connu. J'ai ainsi perdu ma vie à écrire pour donner une chance a ce chant». "Envois", en La carte postale, cit., p. 156. Y en Voiles, París, Galilée, 1998, p. 79: "Je voudrais chanter la douceur très seule de mon tallith, la douceur plus douce que la douceur...».

${ }^{16}$ Geoffrey Bennington y Jacques Derrida, Circonfession, París, Seuil, 1992. Cito por la traducción española: Jacques Derrida, Madrid, Cátedra, 1994, p. 160.

${ }^{17}$ Jacques Derrida, "Envois", en La carte postale. De Socrate à Freud et au de-là, París, Flammarion, 1980, p. 132. Y en Chaque fois unique, la fin du monde (présentépar Pascale-Anne Brandt et Michael Naas), Éditions Galilée, 2003. Cito por la traducción española, Cada vez única, el fin del mundo, Valencia, Pretextos, 2005, p. 153: "Todo trabajo es también un proceso de duelo. Todo trabajo en general trabaja en el duelo".

${ }^{18}$ JaCques Derrida, Circonfessions, cit., p. 97.

${ }^{19}$ Jacques Derrida, Chaque fois unique, la fin du monde (présenté par Pascale-Anne Brandt et Michael Naas), Éditions Galilée, 2003. Cito por la traducción española, Cada vez única, el fin del mundo, Valencia, Pretextos, 2005, p. 11 (subraya Jacques Derrida).

${ }^{20}$ En "Survivre", Parages, París, Éditions Galilée, 1986. Y en Cada vez única, el fin del mundo, cit., pág. 280: “...más allá de todo lo que una lectura precipitada nos haría creer [...] Maurice Blanchot sólo amó y sólo afirmó la vida y el vivir, y la luz de todo lo que se manifestaba”.

21 "La literatura es una invención muy joven que inmediatamente, por sí misma, fue amenazada de muerte. Se piensa, piensa su propia posibilidad, repite su nacimiento desde su fin, desde una finitud que no 
está delante de ella sino en ella, como su recurso y su espectro esencial. Sin duda, Blanchot es quien, cerca de nosotros, dio el mayor Igor tanto al pensamiento como a la posibilidad de esa experiencia inaudita”, en Jacques Derrida-Élisabeth Roudinesco, De quoi demain..., París, Librairie Arthème Fayard et Éditions Galilée, 2001. Cito por la traducción castellana, y mañana qué..., Buenos Aires, Fondo de Cultura Económica, 2003, p. 142.

${ }^{22}$ Jacques Derrida, "Envois", en La carte postale. De Socrate à Freud et au de-là, París, Flammarion, 1980, p. 114.

${ }^{23}$ JaCques Derrida, De quoi demain..., op. cit., p. 59.

${ }^{24}$ JaCQUes Derrida, "Le ruban de machine à écrire", en: Papier machine, París, Éditions Galilée, 2003.

${ }^{25}$ JaCques Derrida, De quoi demain..., op. cit., p. 59.

${ }^{26}$ JaCQues Derrida, De quoi demain..., op. cit, p. 67: "Siempre hubo fenómenos de reproducción, de articulación entre la máquina y lo viviente. La historia de la literatura [...] está constituida por ese tipo de cosas, por funciones casi maquinales y automáticas, siempre en el límite del plagio (noción tan oscura y problemática como la del clon".

${ }^{27}$ Por ejemplo en "Survivre”, Parages, op. cit., p. 152: «Chaque texte est une machine à multiples têtes lectrices pour d'autres textes».

28 "Envíos", op. cit., p. 221.

${ }^{29}$ Circonfessions, op. cit.

30 "Envois", op. cit., p. 178.

31 "Envois", op. cit., p. 240.

32 Hélène Cixoux-Jacques Derrida, Savoir, París, Editions Galilée, 1998.

33 JaCQues Derrida, op. cit., p. 22.

${ }^{34}$ JaCQues Derrida, Signéponge, París, Seuil, 1988.

35 JaCQues Derrida, "La lengua no pertenece", en Diario de poesía, N ${ }^{\circ}$ 58, primavera de 2001. Es un reportaje de Évelyne Grossman publicado en Europe, a. 79, № 861-862, enero-febrero 2001.

36 Jacques Derrida, Donner la mort, Éditions Galilée, París, 1999, y también en L'Étique du don. Jacques Derrida et la pensée du don, París, Métaillé-Transition, 1992.

${ }^{37}$ JaCques Derrida, "Un ver à soie", en Voiles, op. cit. 